$5-7-2010$

\title{
High Strength and Light-weight Materials Inspired by the Exoskeleton of Arthropods
}

Anette M. Karlsson

Cleveland State University, a.karlsson@csuohio.edu

Follow this and additional works at: https://engagedscholarship.csuohio.edu/enme_facpub

Part of the Mechanical Engineering Commons

How does access to this work benefit you? Let us know!

\section{Recommended Citation}

Karlsson, Anette M., "High Strength and Light-weight Materials Inspired by the Exoskeleton of Arthropods" (2010). Mechanical Engineering Faculty Publications. 232.

https://engagedscholarship.csuohio.edu/enme_facpub/232

This Report is brought to you for free and open access by the Mechanical Engineering Department at EngagedScholarship@CSU. It has been accepted for inclusion in Mechanical Engineering Faculty Publications by an authorized administrator of EngagedScholarship@CSU. For more information, please contact library.es@csuohio.edu. 


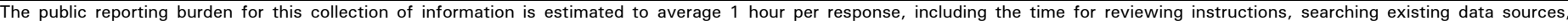

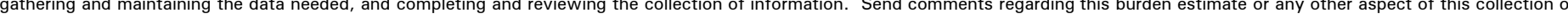

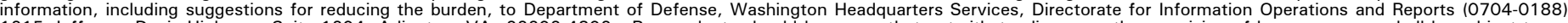

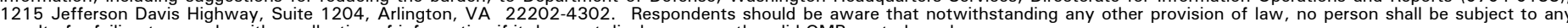
penalty for failing to comply with a collection of information if it does not display a currently valid OMB control number.

PLEASE DO NOT RETURN YOUR FORM TO THE ABOVE ADDRESS.
1. REPORT DATE $(D D-M M-Y Y Y Y)$ 2. REPORT TYPE
05-07-10
Final Report
3. DATES COVERED (From - To)
$1 / 1 / 09-9 / 30 / 09$

4. TITLE AND SUBTITLE

ARO Exoskeleton Materials

5a. CONTRACT NUMBER

5b. GRANT NUMBER

W911NF-08-1-0493

5c. PROGRAM ELEMENT NUMBER

6. AUTHOR(S)

Dr. Anette M. Karlsson

\section{5d. PROJECT NUMBER}

55016MSIIMS06214

5e. TASK NUMBER

5f. WORK UNIT NUMBER

\section{PERFORMING ORGANIZATION NAME(S) AND ADDRESS(ES)}

University of Delaware

Mechanical Engineering REPORT NUMBER

MEEG33213409000

\section{SPONSORING/MONITORING AGENCY NAME(S) AND ADDRESS(ES)}

University of Delaware

220 Hullihan Hall

Newark, DE 19716-0099

11. SPONSOR/MONITOR'S REPORT NUMBER(S)

\section{DISTRIBUTION/AVAILABILITY STATEMENT}

Approved for public release; distribution unlimited

\section{SUPPLEMENTARY NOTES}

\section{ABSTRACT}

This work investigates the multiscaled structure and the constitutive behavior of the exoskeleton of arthropods (Japanese beetle) along with the response of biomimicked structures. Image analysis (SEM and TEM) revealed three load-bearing regions comprised of chitin-protein fiber layers orientated parallel to the cuticle surface. The chitin fibers in the exocuticle and mesocuticle are organized in a helicoidal structure (layers stacked with a small rotational angle relative to their adjacent layers). The endocuticle has a distinct pseudo-orthogonal pattern, characterized by a thin transitional helicoidal region inserted between two orthogonal layers. Idealized mechanics based models showed that the pseudo-orthogonal structure redistributes the stresses, and reduces the maximum tensile stress and transverse shear stress in the cross-section, thus making the structure able to tolerate larger external loads. Furthermore, the interfacial strain energy release rate is lower in the pseudo-orthogonal structure compared to the cross-ply laminate, suggesting that the pseudo-orthogonal structure may be more resistant to fracture. The bio-inspired laminated composite 15. SUBJECT TERMS

biomimicking, composite materials, durability

\begin{tabular}{|c|c|c|}
\hline \multicolumn{3}{|c|}{ 16. SECURITY CLASSIFICATION OF: } \\
\hline a. REPORT & b. ABSTRACT & c. THIS PAGE \\
U & $\mathrm{U}$ & $\mathrm{U}$ \\
\hline
\end{tabular}

17. LIMITATION OF
ABSTRACT
U

18. NUMBER OF PAGES 19a. NAME OF RESPONSIBLE PERSON

Dr. Anette Karlsson

19b. TELEPHONE NUMBER (Include area code)

302-831-2421 


\section{INSTRUCTIONS FOR COMPLETING SF 298}

1. REPORT DATE. Full publication date, including day, month, if available. Must cite at least the year and be Year 2000 compliant, e.g. 30-06-1998; $x x-06-1998 ; x x-x x-1998$.

2. REPORT TYPE. State the type of report, such as final, technical, interim, memorandum, master's thesis, progress, quarterly, research, special, group study, etc.

3. DATES COVERED. Indicate the time during which the work was performed and the report was written, e.g., Jun 1997 - Jun 1998; 1-10 Jun 1996; May - Nov 1998; Nov 1998.

4. TITLE. Enter title and subtitle with volume number and part number, if applicable. On classified documents, enter the title classification in parentheses.

5a. CONTRACT NUMBER. Enter all contract numbers as they appear in the report, e.g. F33615-86-C-5169.

5b. GRANT NUMBER. Enter all grant numbers as they appear in the report, e.g. AFOSR-82-1234.

5c. PROGRAM ELEMENT NUMBER. Enter all program element numbers as they appear in the report, e.g. 61101A.

5d. PROJECT NUMBER. Enter all project numbers as they appear in the report, e.g. 1F665702D1257; ILIR.

5e. TASK NUMBER. Enter all task numbers as they appear in the report, e.g. 05; RF0330201; T4112.

5f. WORK UNIT NUMBER. Enter all work unit numbers as they appear in the report, e.g. 001; AFAPL30480105.

6. AUTHOR(S). Enter name(s) of person(s) responsible for writing the report, performing the research, or credited with the content of the report. The form of entry is the last name, first name, middle initial, and additional qualifiers separated by commas, e.g. Smith, Richard, J, Jr.

\section{PERFORMING ORGANIZATION NAME(S) AND} ADDRESS(ES). Self-explanatory.

\section{PERFORMING ORGANIZATION REPORT NUMBER.} Enter all unique alphanumeric report numbers assigned by the performing organization, e.g. BRL-1234; AFWL-TR-85-4017-Vol-21-PT-2.

\section{SPONSORING/MONITORING AGENCY NAME(S)} AND ADDRESS(ES). Enter the name and address of the organization(s) financially responsible for and monitoring the work.

10. SPONSOR/MONITOR'S ACRONYM(S). Enter, if available, e.g. BRL, ARDEC, NADC.

\section{SPONSOR/MONITOR'S REPORT NUMBER(S).}

Enter report number as assigned by the sponsoring/ monitoring agency, if available, e.g. BRL-TR-829; -215.

12. DISTRIBUTION/AVAILABILITY STATEMENT. Use agency-mandated availability statements to indicate the public availability or distribution limitations of the report. If additional limitations/ restrictions or special markings are indicated, follow agency authorization procedures, e.g. RD/FRD, PROPIN, ITAR, etc. Include copyright information.

13. SUPPLEMENTARY NOTES. Enter information not included elsewhere such as: prepared in cooperation with; translation of; report supersedes; old edition number, etc.

14. ABSTRACT. A brief (approximately 200 words) factual summary of the most significant information.

15. SUBJECT TERMS. Key words or phrases identifying major concepts in the report.

16. SECURITY CLASSIFICATION. Enter security classification in accordance with security classification regulations, e.g. $U, C, S$, etc. If this form contains classified information, stamp classification level on the top and bottom of this page.

17. LIMITATION OF ABSTRACT. This block must be completed to assign a distribution limitation to the abstract. Enter UU (Unclassified Unlimited) or SAR (Same as Report). An entry in this block is necessary if the abstract is to be limited. 
Final Report ARO W911NF-08-1-0493

\title{
High Strength and Light-weight Materials Inspired by the Exoskeleton of Arthropods
}

\author{
Anette Karlsson, Dept. Mechanical Engineering. University of Delaware, January 2010
}

\section{Objectives}

The overall objective of the proposed work was to establish the multiscaled structure and the constitutive behavior of exoskeleton of arthropods. The following tasks are defined for the proposed short term investigation: (1) Establish the morphology of the multiscale structure for selected exoskeleton materials through careful and systematic image analyses; (2) Explore the mechanical properties; (3) Simulate characteristic structural response of the exoskeleton using mechanics based numerical models and investigate how these structural responses can be translated into engineering materials.

\section{Summary of Results}

(1) Morphology of the multiscale structure for a Japanese Beetle

We investigated the exoskeletal microstructure of a common insect, Popillia japonica (Japanese beetle). This structure was compared to a previous study, where Homarus americanus (American lobster) and Callinectes sapidus (Atlantic blue crab) were investigated [1].

Image analysis via SEM and TEM revealed a common morphology in cuticles from the pronotum, leg and elytron. All exoskeletons consist of four regions, including (from external surface and inwards and corresponding to increasing thickness) epicuticle, exocuticle, mesocuticle and endocuticle, fig. 1 [2]. The latter three regions are the load-bearing structures and are comprised of chitin-protein fiber layers orientated parallel to the cuticle surface. The chitin fibers in the exocuticle and mesocuticle are organized in a helicoidal structure, which is characterized by layers stacked with a small rotational angle relative to their adjacent layers, Fig 1B, Fig. 2A, B. The endocuticle has a distinct pseudo-orthogonal pattern, which is characterized by a thin transitional helicoidal region inserted between two orthogonally stacked layers Fig. 2C, Fig 3.

Idealized mechanics based models of orthogonally layered structures with and without the helicoidal transitional region (corresponding to the pseudo-orthogonal and conventional crossply laminates respectively) were developed for evaluating the endocuticle's mechanical response within the linear elastic range, Fig. 4. The mechanical response of the conventional cross-ply laminate includes discontinuity of the normal stress (Fig 5A) and transverse shear strain (Fig 6B) at the interfaces of the orthogonal laminae due to the discontinuous material properties (assuming laminate theory within the framework of continuum mechanics). The introduction of a pseudo-orthogonal structure results in a redistribution of the stress and strain fields, including smaller discontinuities between the layers and more uniform stress and strain distribution over the cross-section, Figs. 5 and 6. The pseudo-orthogonal structure results in reduced maximum tensile stress and transverse shear stress in the across-section. The magnitude of the discontinuity (jump) in the normal stress and shear strain is significantly reduced as well. Furthermore, the interfacial strain energy release rate of the laminate is lower in the pseudoorthogonal structure compared to the cross-ply laminate, suggesting that the pseudo-orthogonal structure may be more resistant to fracture. 
Laminated composite structures were designed and manufactured with bio-inspired structural patterns. To investigate how the layup sequence affect man-made materials, four model configurations characterized by distinctive stacking-sequence were developed: (1) a baseline structure (BL), which is widely used in industry as a quasi-isotropic structure; (2) a "single helicoidal" structure (SH) with its stacking sequence directly replicated from the nature designed helicoidal structure; and two variations (3) a "double helicoidal” structure (DH) and (4) a "single helicoidal mid-plane symmetric" structure (SHMS). The last two configurations were developed to address the mid-plane symmetry issue. Uni-directional S2-glass epoxy prepreg was used as model material. We note that we do not believe this is the best suited material system, but believe this well-known material system may reveal imported structural implications. The mechanical performance was evaluated via standard test protocols (ASTM D790 and ASTM D2344), including the flexural stiffness and strength, transverse shear modulus and strength, as well as residual strength. The bio-inspired structure showed improved mechanical properties over the conventional baseline structure that is widely used in industry, including the bending stiffness (Fig. 7) and the residual strength under static load (Fig. 8). The improvement was more significant when a "smaller" fiber rotation was used, such as the SH and SHMS structures. Also, the warping problem during practical manufacturing was addressed by enforcing mid-plane symmetry in the laminate design; meanwhile the mechanical advantages of the bio-material system were still retained. The improvement on the mechanical performance observed in the bioinspired structure underscored the advantages of the helicodial structural pattern. With proper combination with the practical manufacturing wisdom, such as mid-plane symmetry, the nature designed helicoidal structure possessed great potential in future practical application.

\section{Conclusion}

The results reveal interesting aspects of the strategy of the nature in designing and manufacturing functional biomaterial systems. These observations may be used to inspire and improve man-made materials and structures. Preliminary work indicates that the layup have clear potential for superior residual strength after initial failure.

\section{References:}

[1] Cheng L, Wang LY and Karlsson AM, Image analyses of two crustacean exoskeletons and implications of the exoskeletal microstructure on the mechanical behavior. Journal of Materials Research 23(11): 2854-2872 (2008)

[2] Cheng L, Wang LY and Karlsson AM,, Mechanics based analysis of selected features of the exoskeletal microstructure of Popillia japonica, J Materials Research, 24(11) 3253-3267 (2009)

[3] Cheng L, Glancey JL and Karlsson AM, Mechanical behavior of bio-inspired laminate composites, in review 


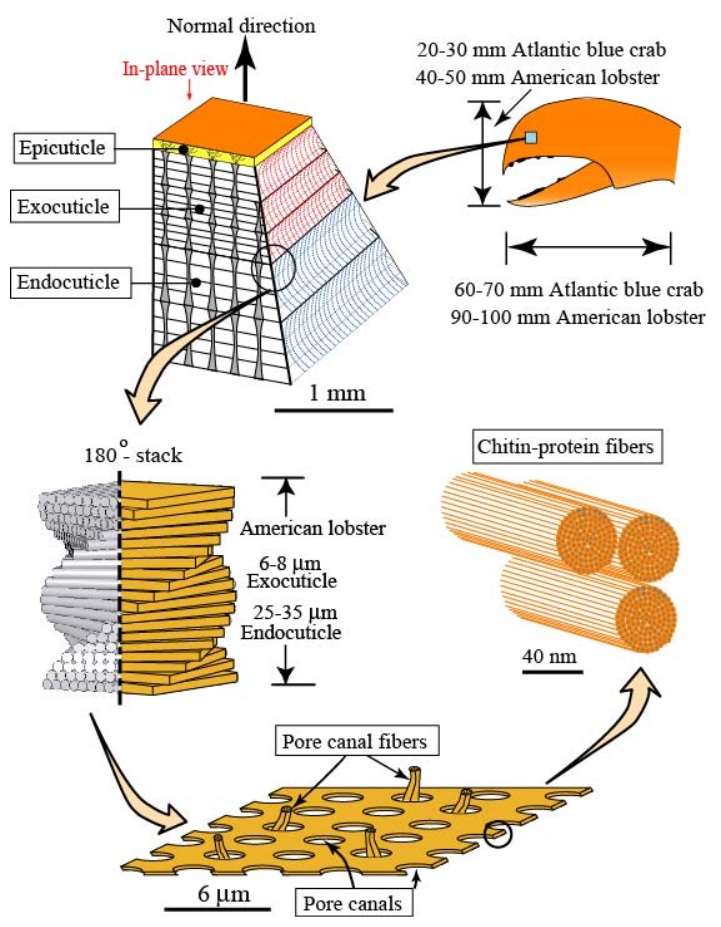

(A) Blue Crab and Lobster

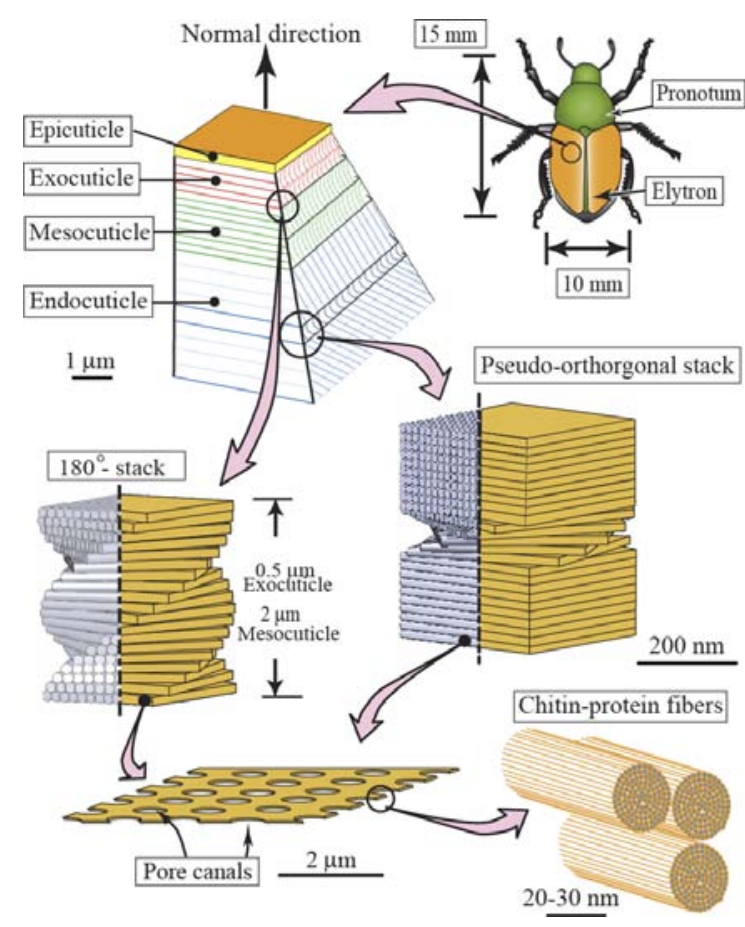

(B) Japanese Beetle

Fig. 1 Schematic of the upper structural levels of a (A) Homarus americanus (American lobster) exoskeleton [1] and (B) Popillia japonica (Japanese beetle) exoskeleton [2]. In both cases, the epicuticle, a diffusion barrier, is not a structural load bearing layer The exocuticle, mesocuticle (beetle only) and endocuticle are the main load bearing structures composed of fibrous chitin-protein fibers organized as either helicoidal or pseudo-orthogonal structures.

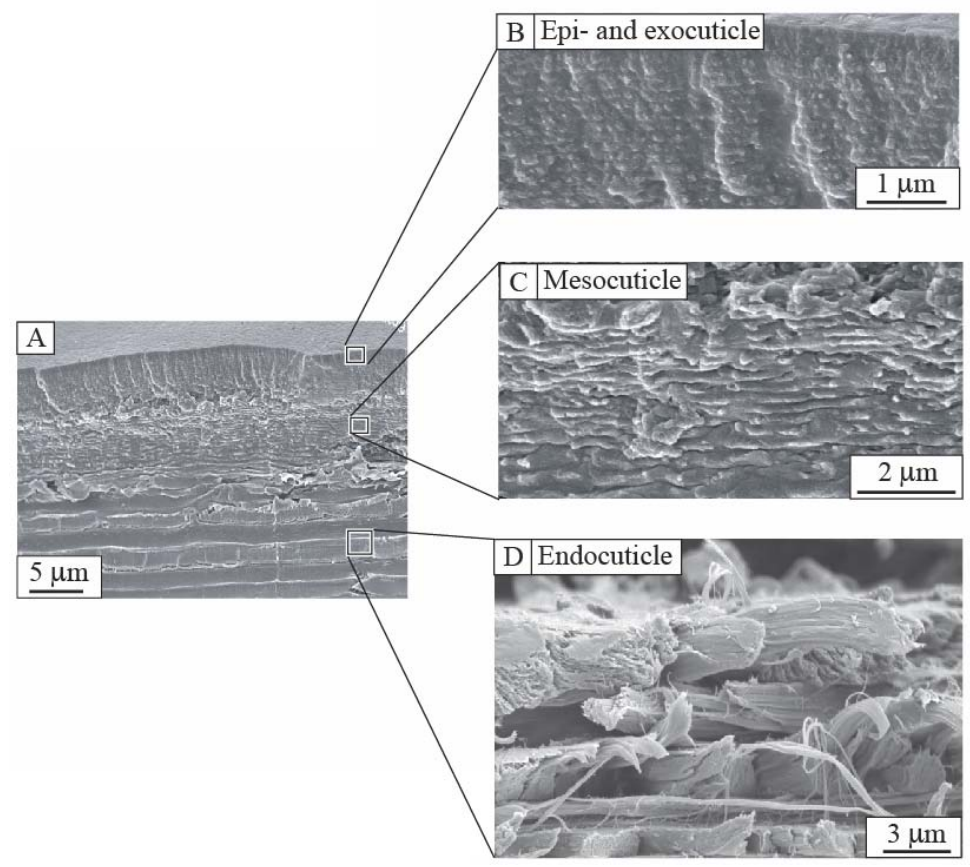

Fig. 2 SEM images of the exoskeleton (elytron) of a Popillia japonica. (A) Overview of the cross-section; (B) Epicuticle and exocuticle ( 2 $\mu \mathrm{m}$ thick); (C) Mesocuticle (7-7.5 $\mu \mathrm{m}$ thick); and (D) Endocuticle (10-11 $\mu \mathrm{m}$ thick). The stacking of two orthogonal layers is shown in the endocuticle.[2] 

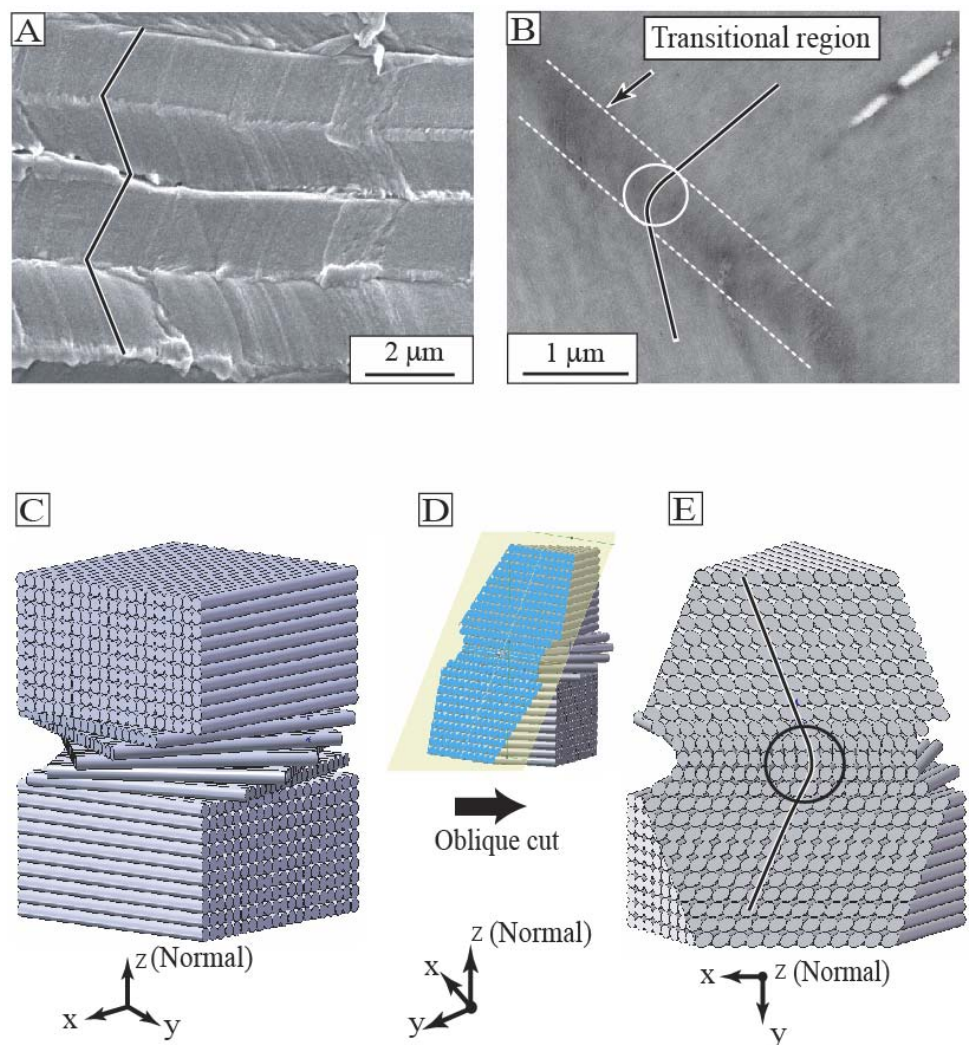

Fig. 3 The pseudo-orthogonal pattern of the chitin-protein fibers in the endocuticle. (A) A zigzag pattern seen in a SEM image of an oblique section of the endocuticle from the Popillia japonica elytron; (B) A TEM image of an oblique section of the endocuticle, suggesting a helicoidal transitional region (parabolic pattern) between the two orthogonal layers (the size of the transitional region appears to be thicker than the true thickness since it is observed from an oblique section); (C) A schematic representation of the pseudo-orthogonal pattern: The two orthogonally stacked unidirectional layers each consists of parallel fibers. A thin transition region assembling a helicoidal structure (Bouligand-structure) joins the two orthogonal layers; (D) An oblique cut in the pseudoorthogonal block; (E) The side view of the oblique cut displays the zigzag and parabolic pattern seen in (A) and (B). [2]

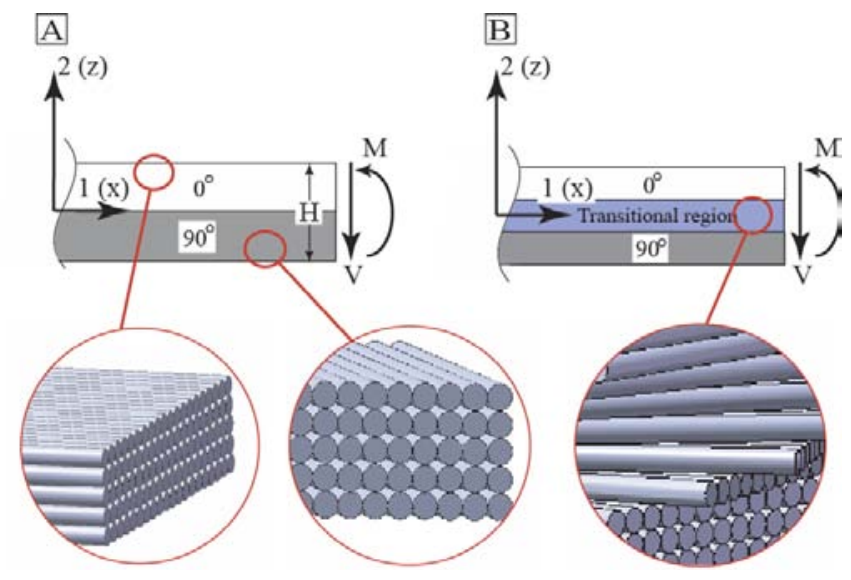

Fig. 4 Models of (A) the traditional cross-ply laminate and (B) bio-inspired pseudo-orthogonal laminate of thickness, $\mathrm{H}$. The cross-sections of the laminates are subjected to the general load of bending moment $\mathrm{M}$ and shear force $\mathrm{V}$ (load per unit width). The schematic enlargement of each region indicates the fiber orientation in the corresponding region. [2] 

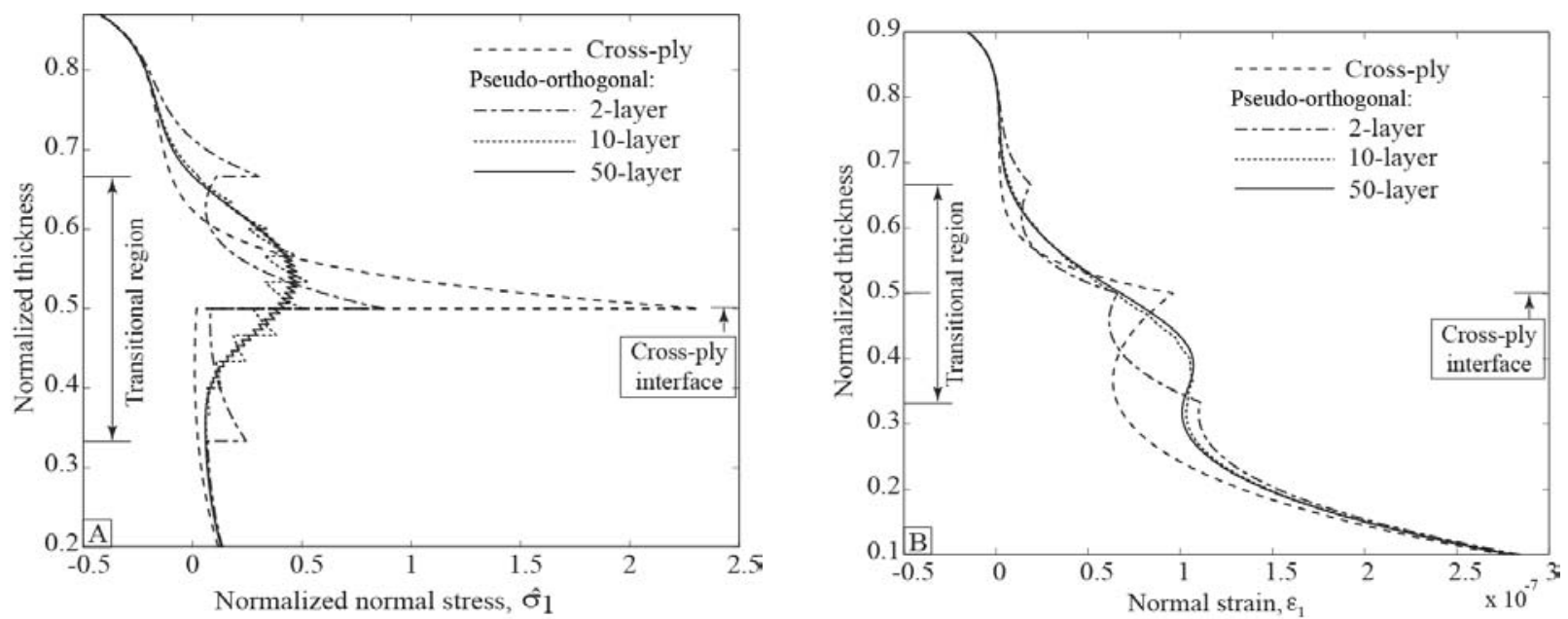

Fig. 5 (A) Normalized normal stress and (B) normal strain distribution over the cross section of the laminate with selected numbers of lamina in the transitional region.[2]
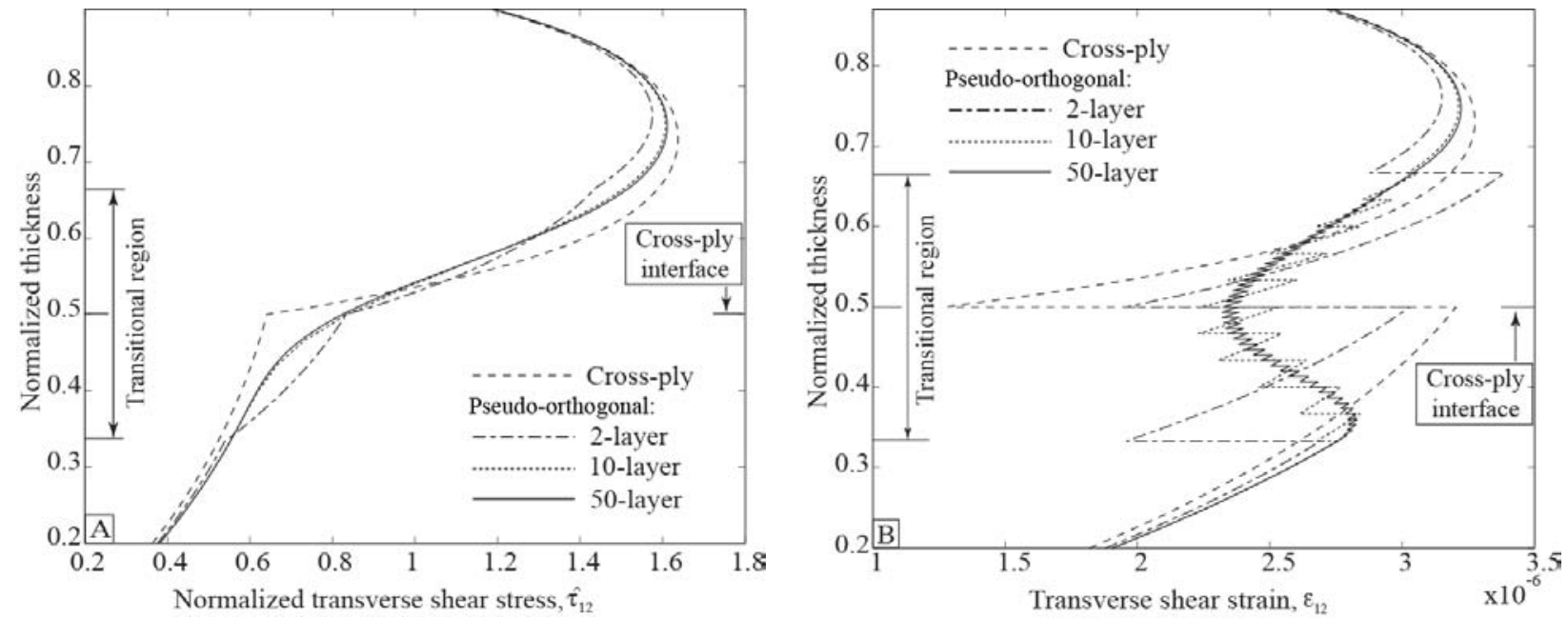

Fig. 6 (A) Normalized transverse shear stress and (B) strain distributions over the cross section of the laminate with selected numbers of lamina in the transitional region. [2] 


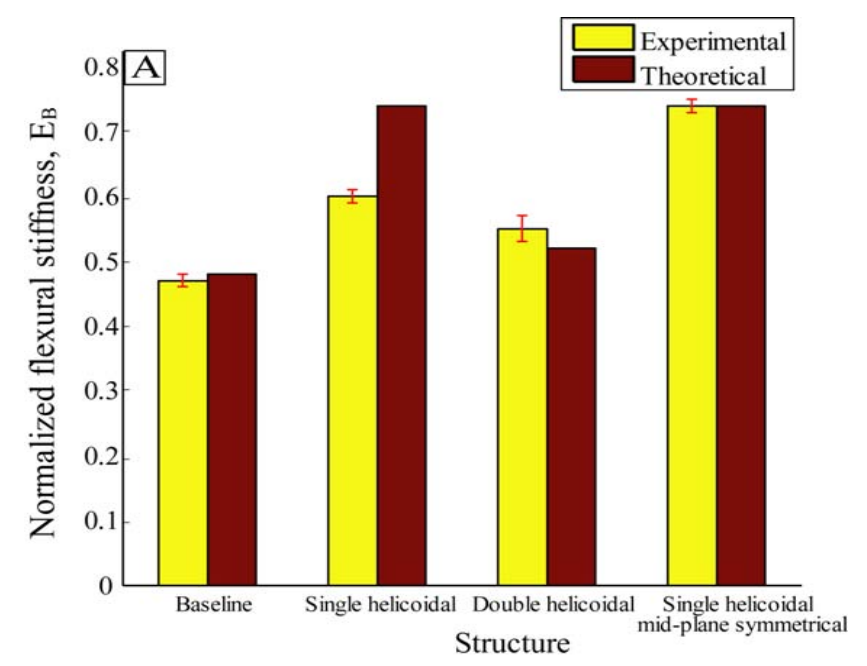

Fig. 7 Normalized flexural stiffness of laminates beams with different structures from the "long beam test” (ASTM D790). [3]

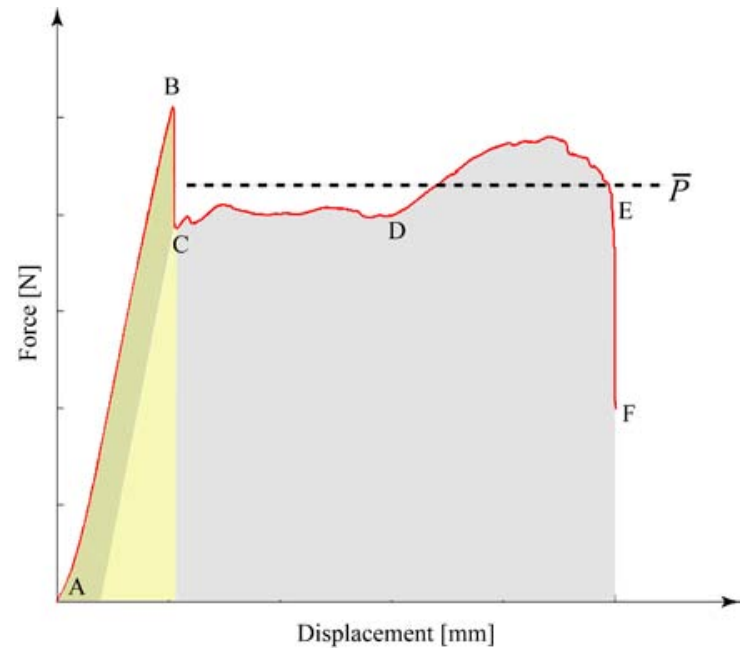

(A)

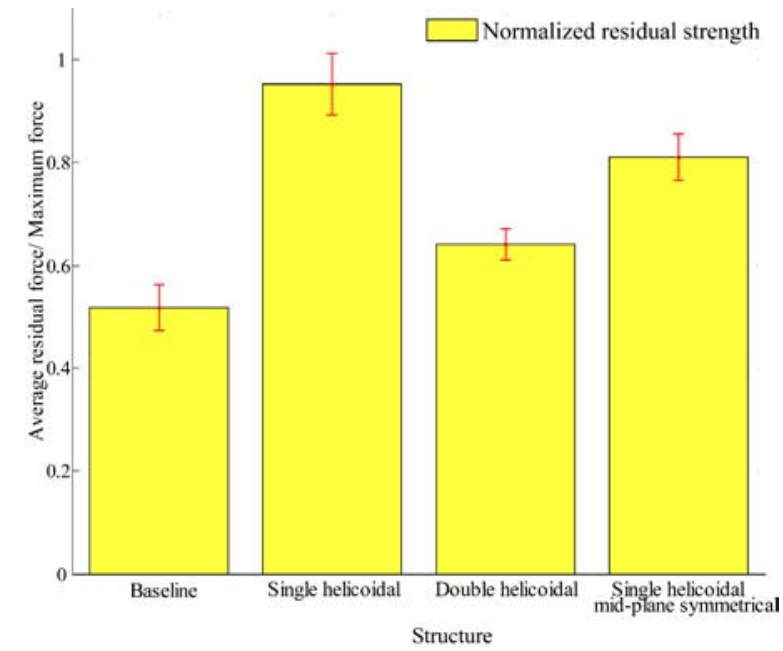

(B)

Fig. 8 (A) A typical force-displacement curve from the "short beam test" (ASTM D2344). $\overline{\boldsymbol{P}}$ is the average residual force after the onset of initial damage. (B) Normalized residual strength of laminated composites with different structures. The red bar indicates the standard deviation of the result in each group. [3] 